\title{
Cytokine Storm and its Implication in Coronavirus disease 2019 (COVID-19)
}

\author{
Chandreyee Datta, Ashish Bhattachariee* \\ Department of Biotechnology, National Institute of Technology, Durgapur, 713209, West Bengal, India.
}

\section{Article Info}

\section{Article Notes}

Received: August 25, 2020

Accepted: September 18, 2020

\section{${ }^{*}$ Correspondence:}

Dr. Ashish Bhattacharjee, Department of Biotechnology, National Institute of Technology, Durgapur-713209, West Bengal, India; Email: ashish15lo@yahoo.com

C 2020 Bhattacharjee A. This article is distributed under the terms of the Creative Commons Attribution 4.0 International License.

\section{Keywords:}

COVID-19

SARS-CoV-2

Cytokine storm syndrome

Interleukin

Hyperinflammation

ARDS

\begin{abstract}
Corona virus disease 2019 (COVID-19), is a viral disease caused by novel corona virus known as severe acute respiratory syndrome corona virus 2 (SARS-CoV-2). The disease was declared as a pandemic by the World Health Organisation (WHO) on March 11, 2020. Initial studies have shown the molecular resemblances in the receptor binding domains of SARS-CoV and SARS-CoV-2 which bind angiotensin converting enzyme 2 (ACE 2) receptors and helps the virus to enter into the host cells to cause infection. Illness caused by COVID19 ranges from mild common cold to life threatening acute respiratory distress syndrome (ARDS), multi-organ dysfunction and shock. The key step in converting mild disease to severe is immune dysfunction and cytokine dysregulation resulting in "cytokine storm syndrome". Clinical investigations in patients with COVID-19 have shown that a strong upregulation of cytokine and interferon production is common feature in SARS-CoV2-induced pneumonia, with an associated cytokine storm syndrome. Consequently, spotting of existing approved therapies with proper safety profiles to treat hyperinflammation is very essential in order to reduce COVID-19 associated mortality. Till date, no specific therapeutic drugs or vaccines are available to treat COVID-19. In this review, we intended to describe how cytokine storm is associated with the severity of COVID-19 disease and also tried to find out the best possible way to manage the hyperinflammatory response due to cytokine storm during COVID-19 infection using several interleukin receptor antagonists, inhibitors, intravenous immunoglobulins, cytokine adsorption device and repurposing of pre-existing antiviral and some antimalarial drugs etc.
\end{abstract}

\section{Introduction}

Corona virus disease 2019 (COVID-19) is a new but widely prevalent clinical entity, first reported as an outbreak of pneumonia in Wuhan, China on December 2019. After that, a new virus called 2019-nCoV, was isolated on January 7, 2020 and identified as the causative agent of the outbreak ${ }^{1}$. This newly identified virus already affected a substantial proportion of people worldwide in a short span of time and was declared as a pandemic by the World Health Organisation (WHO) on March 11, $2020^{2}$.

Corona viruses are basically enveloped RNA viruses whose disease causing ability varies widely from common cold to severe pneumonia. This family has also a notorious historical background of being responsible for two major outbreaks in the past including severe acute respiratory syndrome (SARS-CoV) in 2002 and Middle east respiratory syndrome (MERS-CoV) in 2012 ${ }^{3}$. The emergence of Middle East respiratory syndrome coronavirus (MERS-CoV) in 2012 marked the second introduction of a highly pathogenic coronavirus into the human population in the twenty-first century. Scientific advancements after the 2002-2003 severe acute 
respiratory syndrome coronavirus (SARS-CoV) pandemic helped for the rapid progress in our understanding of the epidemiology and pathogenesis of MERS-CoV and the development of therapeutics ${ }^{3}$.

The Coronaviridae Study Group (CSG) of the International Committee on Taxonomy of Viruses, has assessed the placement of the human pathogen, tentatively named 2019-nCoV, within the Coronaviridae family. The CSG recognizes this virus as forming a sister clade to the prototype human and bat severe acute respiratory syndrome coronaviruses (SARS-CoVs) of the species Severe acute respiratory syndrome-related coronavirus, and designates it as SARS-CoV-2 based on phylogeny, taxonomy and established practice ${ }^{4}$.

SARS-CoV2 disease and its characteristics can be approximately divided into three phases:

I. asymptomatic phase with or without detectable virus;

II. symptomatic but non-severe phase with upper airway involvement; and

III. severe, potentially lethal disease with hypoxia, 'ground glass' infiltrates in the lung,

and progression to acute respiratory distress syndrome (ARDS) with high viral load ${ }^{5}$.

The genome of CoVs is a single-stranded positivesense RNA (+ssRNA) (approximately of $30 \mathrm{~kb}$ ) with $5^{\prime}$-cap structure and $3^{\prime}$-poly-A tail at the end. This virus genome encodes four major proteins: spike (S), nucleo capsid $(\mathrm{N})$, membrane $(\mathrm{M})$, and envelope (E). The $\mathrm{S}$ protein is responsible for viral entry into target ACE-2 expressing cells of the body. Approximately 75\% of the SARS-CoV2 genome is identical to the SARS-CoV genome, and the amino acid residues required for receptor binding are the same between these two viruses; both viruses use the angiotensin converting enzyme 2 (ACE-2) receptor to infect airway epithelial cells and endothelial cells ${ }^{6,7}$.

There are two measures used to assess the proportion of infected individuals with fatal outcomes. The first is infection fatality rate (IFR), which estimates this proportion of deaths among all infected individuals. The second is case fatality rate (CFR), which estimates this proportion of deaths among identified confirmed cases.

To measure IFR accurately, a complete picture of the number of infections of, and deaths caused by the disease must be known. Consequently, at this early stage of the pandemic, most estimates of fatality ratios have been based on cases detected through surveillance and calculated using crude methods, giving rise to widely variable estimates of CFR by country - from less than $0.1 \%$ to over $25 \%{ }^{8}$.

The COVID-19 poses an increasing threat to humans with an initial case fatality rate (CFR) of around $7.2 \%$ in Italy but later by the end of April 2020, overall CFR reported by routine statistics in Italy, Spain, UK, The Netherlands and France is over $10 \%$ and it is difficult to justify the difference only with the older age of patients ${ }^{8}$.

COVID-19 infection is accompanied by an aggressive inflammatory response with the typical characteristics of an uncontrolled systemic inflammatory response resulting from the release of pro-inflammatory cytokines and chemokines by immune effector cells known as "cytokine storm" ". High blood levels of cytokines and chemokines have been detected in patients with COVID-19 infection, including: IL1- $\beta$, IL1RA, IL7, IL8, IL9, IL10, basic FGF2, GCSF, GMCSF, IFN $\gamma$, IP10, MCP1, MIP1 $\alpha$, MIP1 $\beta$, PDGFB, $\mathrm{TNF} \alpha$, and VEGFA ${ }^{10}$. This cytokine storm triggers a violent inflammatory immune response that contributes to ARDS, multiple organ failure, and finally death in severe cases of SARS-CoV2 infection ${ }^{10}$.

Patients infected with COVID-19 showed higher leukocyte numbers, abnormal respiratory findings and increased levels of plasma pro-inflammatory cytokines 9 , ${ }^{10}$. The direct cause of death from acute COVID-19 involves cytokine storm damage to lungs and multiple organs of the body: heart, kidney and liver, leading to multiple organ exhaustion ${ }^{11}$.

Moreover, the co-morbidities (respiratory, cardiovascular, metabolic, oncologic, complications etc.) associated with this disease result in the deterioration of the immune system which plays a role in the worst outcomes specially observed in the cases of elderly patients ${ }^{11}$. It is well established that during childhood and adolescence, there are instead very high numbers of naïve $\mathrm{T}$ lymphocytes, ready to differentiate and to engage a successful fight against eventual new pathogens ${ }^{12}$. As a consequence, children are currently paying a very low death toll to SARSCoV2 infection indeed. Current management of COVID-19 is supportive with an ongoing persistent struggle for the development of novel therapeutics like antivirals and vaccines. Meanwhile, it is equally important to identify and treat hyperinflammation caused by cytokine storm with existing approved therapies, to cartel down the mortality rate from COVID-19.

On the basis of the above considerations, the present review is focused on the pathobiology of SARS-CoV2induced cytokine storm, the mechanisms underpinning the lung damage induced by the cytokine storm, as well as on the potential therapies targeting such a very severe condition.

\section{Mechanisms of viral infection}

Like SARS (Severe Acute Respiratory Syndrome) ${ }^{3}$ and MERS (Middle East Respiratory Syndrome) ${ }^{3}$, SARS-CoV-2 is an enveloped, positive-sense and single-stranded RNA $\beta$ 
corona virus ${ }^{4,13}$. It's nucleocapsid contains genomic RNA and a phosphorylated $\mathrm{N}$ protein, which is embedded within phospholipid bilayers and surfaced by two spike proteins ${ }^{14}$. The latter include the spike glycoprotein trimmer (S) and the hemagglutinin-esterase (NE), among which the type III transmembrane glycoprotein $\mathrm{M}$ and the envelope $\mathrm{E}$ protein are interposed ${ }^{14}$. The $S$ glycoprotein binds to the cell membrane receptor ACE2, expressed within the lower respiratory tract by type 2 alveolar epithelial cells ${ }^{14}$. This key function of S glycoprotein is primed by TMPRSS2, a human type 2 transmembrane serine protease, which thus facilitates virus entry into host cells ${ }^{14}$. The $\mathrm{S}$ glycoprotein comprises a S1 subunit mediating the cellular tropism of SARS-CoV2, and a S2 subunit that is responsible for virus-cell membrane fusion ${ }^{14}$. This fusion is followed by penetration of viral genomic RNA into the cytoplasm. Once inside the target cells, single-stranded viral RNA is recognised by the intracellular Toll-like receptor 7 (TLR7) located in endosomes ${ }^{14}$. As a consequence of this infectious process, SARS-CoV2 RNA drives the translation and assembly of viral proteins inside the endoplasmic reticulum and Golgi apparatus. The newly formed vesicles, which contain viral particles, fuse with cell membrane thus releasing the virus.

In case of both SARS and SARS-CoV2, the spike protein (S) interacts with angiotensin converting enzyme 2 (ACE2) in both the cases. Compared to SARS, the affinity of the spike protein $S$ towards the ACE2 receptor is much higher in case of SARS-CoV2 and hence the infectivity is much higher in case of SARS-CoV2. However, SARS-CoV2 protein is longer than SARS-CoV S protein and it's receptor binding region is completely different. Moreover, SARS-CoV nucleocapsid (N) protein has the ability to neutralize the immune response of the host, acting as an antagonist to the action of IFN- $\gamma$, and till now, there is no such reports showing that SARSCoV2 $\mathrm{N}$ protein exhibits the same ability. So, this would partly explain why SARS-CoV has a higher mortality rate than SARS-CoV-2 ${ }^{15}$.

Secondly, the R0 ( $\mathrm{R}$ through) of SARS-CoV-2 is 2- to 3 -fold higher than the R0 of SARS-CoV $(<1)$. Usually, the main characteristics of high R0 is highly diffusible infections, with a long incubation time. For this reason also SARS-CoV2 is associated with mild-to-moderate symptoms or latent infection and is associated with a low mortality rate ${ }^{15}$.

\section{Consequence of impaired immune response}

Tissue destruction is a common feature of SARS-CoV2infected cells, which triggers innate immune responses mediated mostly by macrophages. Indeed, tight intercellular communications occur between ACE2-expressing lung epithelial cells and macrophages ${ }^{14}$. In context of class I major histocompatibility complex (MHC-I), macrophages present viral antigens to $\mathrm{T}$ lymphocytes, thereby leading to
T cell subset commitment and activation ${ }^{16}$. The subsequent Th1-featured adaptive immune response should contribute to clear viral infection via the release of antiviral cytokines such as type I interferons (IFNs). However, previously published article reported that severe infections caused by SARS coronavirus may be associated with low levels of IFN production ${ }^{17}$. Therefore, this pathobiologic scenario could be characterised by polarisation towards an aberrant $\mathrm{T}$ cell lineage and a dysregulated cytokine secretory pattern. In fact, it has been shown recently thatSARS-CoV2 infection can prime $\mathrm{CD}^{+}{ }^{+} \mathrm{T}$ lymphocytes to differentiate into pathogenic Th1 cells, secreting high amounts of interleukin-6 (IL-6) and granulocyte macrophage-colony stimulating factor (GM-CSF) ${ }^{18}$. Such a cytokine milieu promotes activation of $\mathrm{CD}_{14}{ }^{+}$and $\mathrm{CD}_{16} 6^{+}$monocytes, which in turn release IL-6 and may migrate from blood to lung, thus possibly becoming non-resident inflammatory macrophages or dendritic cells ${ }^{18}$. In addition, severely ill COVID-19 patients develop dysfunctional immune-phenotypes of $\mathrm{CD}^{+}$and $\mathrm{CD}^{+} \mathrm{T}$ lymphocytes, characterised by a high coexpression of surface markers such as PD-1 (programmed cell death protein-1) and Tim-3 (T-cell immunoglobulin and mucin domain containing-3), which predisposes to a rapid $\mathrm{T}$ cell exhaustion during viral infections. In fact, in patients with severe disease, innate immune mechanisms can fail to induce an effective virus-targeted cytotoxic response, normally implemented by activated $\mathrm{CD}^{+}$cells ${ }^{19}$. Furthermore, the adaptive immune response induced by SARS-CoV2 might also be shaped as a predominant Th17 profile ${ }^{20}$.

\section{Hemophagocytic lymphohistiocytosis and cytokine storm in COVID 19}

Hemophagocytic syndrome (HPS) or hemophagocytic lymphohistiocytosis (HLH) is an acute and rapidly progressive systemic inflammatory disorder. The most common characteristics of which are cytopenia, excessive cytokine production, and hyperferritinemia. Common clinical manifestations of HLH are acute unremitting fever, lymphadenopathy, hepatosplenomegaly, and multiorgan failure. Due to a massive cytokine release, this clinical condition is considered as a cytokine storm syndrome. HPS has primary and acquired (secondary, reactive) forms. Its primary form is mostly seen in childhood and caused by various mutations with genetic inheritance and, therefore, is called familial HLH. Secondary HLH may be caused in the presence of an underlying disorder, that is, secondary to a malignant, infectious, or autoimmune/autoinflammatory stimulus ${ }^{21}$.

According to the revised HLH-2004 guideline ${ }^{22}$, the diagnosis is based on five criteria (fever, splenomegaly, bicytopenia, hypertriglyceridemia and/ or hypofibrinogenemia, and hemophagocytosis) and three additional criteria: low/absent NK-cell-activity, 
hyperferritinemia, and high-soluble IL-2-receptor levels. Other abnormal clinical and laboratory findings consistent with the diagnosis are cerebromeningeal symptoms, lymph node enlargement, jaundice, edema, skin rash, hepatic enzyme abnormalities, hypoproteinemia, hyponatremia, VLDL increase, and HDL decrease. Five of these eight criteria must be fulfilled, unless family history or molecular diagnosis is consistent with $\mathrm{HLH}^{22}$.

A cytokine profile bear a resemblance to sHLH is associated with COVID-19 disease severity, characterised by increased interleukin (IL)-2, IL-7, granulocyte colony stimulating factor (G-CSF), interferon- $\gamma$ (IFN- $\gamma$ ), inducible protein 10 (IP-10), monocyte chemoattractant protein 1(MCP-1), and tumour necrosis factor- $\alpha$ (TNF- $\alpha$ ) 23. Predictors of fatality from a recent retrospective, multicentre study of 150 confirmed COVID-19 cases in Wuhan, China, included elevated ferritin (mean $1297.6 \mathrm{ng} /$ $\mathrm{ml}$ in nonsurvivors vs $614.0 \mathrm{ng} / \mathrm{ml}$ in survivors; $\mathrm{p}<0.001$ ) and IL- $6(\mathrm{p}<0.0001),{ }^{21}$ suggesting that mortality might be due to virally driven hyperinflammation.

Without early diagnosis and prompt appropriate treatment, the mortality rate of HLH is very high. Therefore, it is recommended that all patients with severe COVID-19 should be screened for hyperinflammation using standard laboratory tests and the HScore ${ }^{22}$ to identify the subgroups of patients for whom immunosuppressive therapy may improve outcomes. Considering the clinical outcome from recent COVID situation, it is quite evident that a different set of criteria may be required to diagnose patients with COVID-19- associated HLH.

\section{Hypercytokinemia in COVID-19}

Cross-talk of innate and adaptive immune responses induce lung epithelial cells, activated monocytes/ macrophages and $\mathrm{T}$ lymphocytes to massively release a vast array of proinflammatory cytokines and chemokines (cytokine storm), like interleukins IL-1ß, IL-2, IL-6, IL-7, IL-8, IL-17, IL-18, IL-33, GM-CSF, interferon- $\gamma$, inducible protein 10 (IP-10), monocyte chemoattractant protein-1 (MCP-1), macrophage inflammatory protein-1 $\alpha$ (MIP-1 $\alpha$ ), tumour necrosis factor- $\alpha$ (TNF- $\alpha$ ) and transforming growth factor- $\beta$ (TGF- $\beta)^{23,24}$.

\section{IL-6 plays a central role in the COVID-19 cytokine storm}

One of the most important cytokines produced as a consequence of SARS-CoV2-induced TLR-7 signalling is IL-6. IL-6 is a pleiotropic proinflammatory mediator which promotes the proliferation of myeloid progenitor cells and contributes in the growth and activation of leukocytes, as well as induces pyrexia and the synthesis of acute phase proteins such as $\mathrm{C}$ reactive protein (CRP) ${ }^{25}$. IL-6 plays a central role in immune responses by stimulating the differentiation of $\mathrm{T}$ follicular helper cells (Tfh) and contributing, together with TGF- $\beta$, for the development of Th17 cells 12, 20. Through activation of the SOCS-3 (suppressor of cytokine signalling-3) pathway, IL-6 can also suppress phosphorylation of signal transducer and activator of transcription-4 (STAT-4), thus impairing the activity of $\mathrm{CD}^{+}$cytotoxic and natural killer T cells ${ }^{12}$, 25. Moreover, through up-regulation of IL-4 and downregulation of IFN- $\gamma$, IL-6 inhibits antiviral Th1 cell commitment and favours Th2 cell differentiation ${ }^{25}$.

IL-6 can suppress the functions of $\mathrm{T}$ lymphocytes, dendritic cells and macrophages which may help to eliminate corona viruses, thereby dampening the ability of the immune system to clear such infections ${ }^{25}$. Therefore, IL-6 overproduction can probably be induced by some viruses such as SARS-CoV2, to escape immune surveillance. A brief overview of contribution of IL- 6 in the cytokine storm and disease progression has been depicted in Figure 1.

High levels of interleukin 6 (IL-6) and Interleukin 8 (IL8) are common characteristics in the acute stage associated with lung lesions in SARS-CoV1 patients. Especially IL-6 has the ability to induce the hyper-innate inflammatory response due to the SARS-CoV1 invasion of the respiratory tract ${ }^{26}$. Although in some murine viral infections, IL-6 plays a protective and essential role in the resolution process; in others like in SARS-CoV1, high levels of IL-6 were associated with severe inflammation and correlated with mortality in the mice ${ }^{27,28}$. This happens also with SARSCoV2 in COVID-19 patients: some retrospective and metaanalysis studies show how elevated IL- 6 and C-reactive protein (CRP) correlate with mortality and severe disease in comparison to moderate disease ${ }^{29}$. Evidence from a meta-analysis of 6 studies revealed 2.9-fold higher mean IL-6 concentrations in patients with complicated COVID-19 than non-complicated disease ${ }^{29}$. More evidence suggests that critically ill patients with severe respiratory failure and SARS-CoV2 have either immune dysregulation or macrophage-activation syndrome, both of which are characterized by proinflammatory cytokines. Two key features of this immune dysregulation are: overproduction of pro-inflammatory cytokines by monocytes and lymphocyte dysregulation with $\mathrm{CD}^{+}$lymphopenia ${ }^{30}$. An interesting fact is that SARS-CoV1 can directly promote IL-6 secretion. Among all SARS-CoV1 structural proteins (nucleocapsid $\mathrm{N}$, spike $\mathrm{S}$, envelop $\mathrm{E}$ and membrane $\mathrm{M}$ ), only the nucleocapsid protein $(\mathrm{N})$ significantly induced the activation of IL- 6 promoter in human airway epithelial cell cultures ${ }^{31}$. IL- 6 gene expression is activated by the $\mathrm{N}$ protein which binds to the NF-kB regulatory element on IL-6 promoter and facilitates its translocation from cytosol to nucleus. The N protein is essential for IL- 6 secretion and deletion of the $\mathrm{C}$-terminus of the $\mathrm{N}$ protein results in the loss of function in the activation of IL- $6^{31}$. 


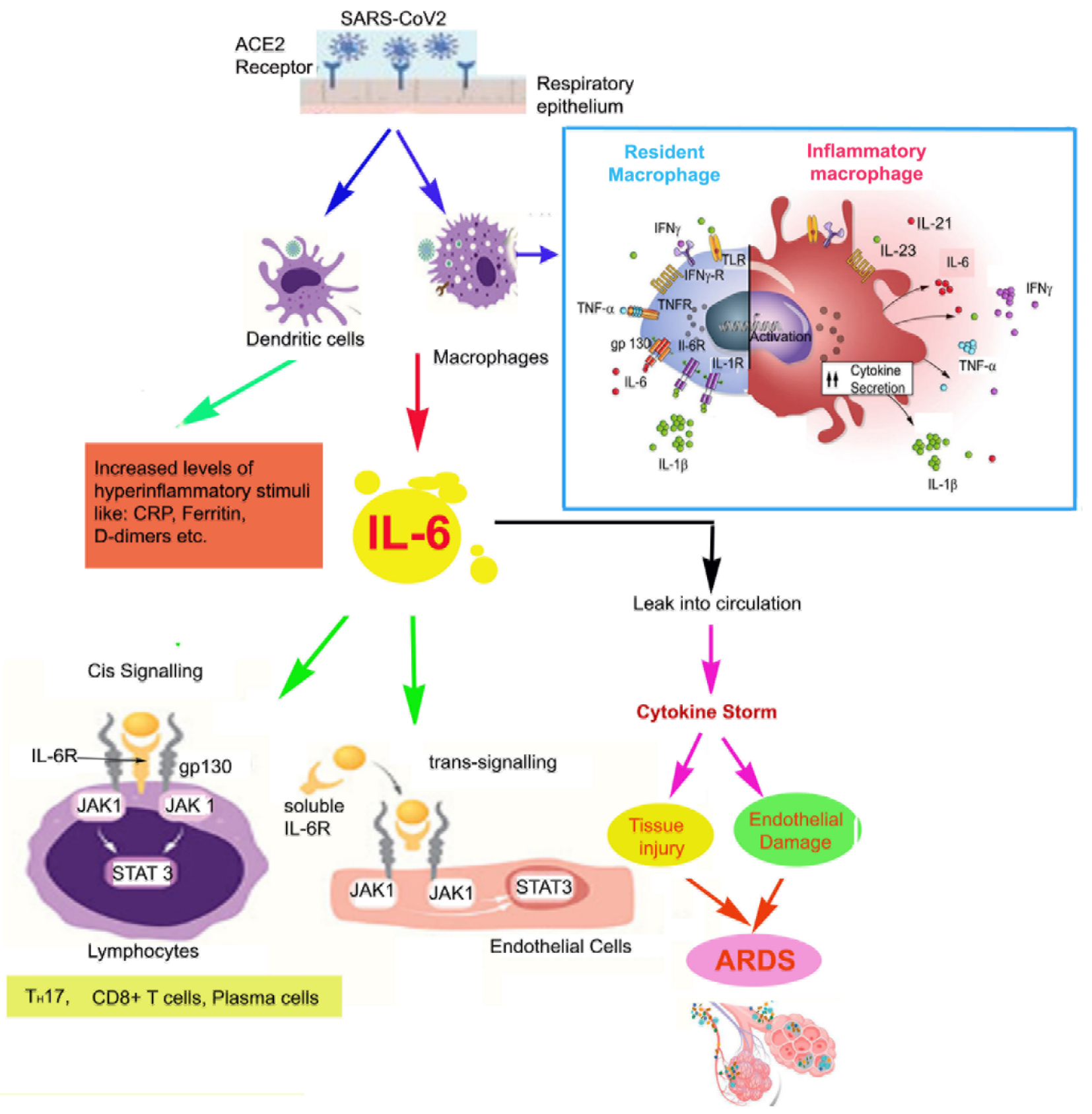

Figure 1: Contribution of IL-6 in Cytokine storm and SARS-CoV2 disease severity

IL-6 has significant pro-inflammatory properties, and it functions through two main signaling pathways: cis or trans. In cis signaling, IL-6 forms a complex with the membrane-bound IL-6 receptor (mIL-6R) and gp130 which then activates downstream the Janus kinases 1 (JAK1) and signal transducer and activator of transcription 3 (STAT3). In trans signaling, high circulating IL- 6 concentrations bind to the soluble form of IL-6 receptor (sIL-6R) and form a complex with a gp130 dimer on most somatic cell types. Another key feature of COVID-19 infection is macrophage activation (especially the monocyte derived macrophages or non-resident macrophages of the lungs which often serve as an indicator of the severe infection), and as a consequence, overproduction of IL-1 $1 \beta$ by the macrophages. IL- $1 \beta$, as well as other proinflammatory cytokines, acts through autocrine stimulation on macrophages leading to a vicious cycle of cytokine production and hyperinflammation. This severely aggravates the "cytokine storm". Cytokine storm finally results in tissue injury and endothelial damage which finally contributes in the most severe form of SARS-CoV2 disease-ARDS.

JAK: Janus Kinase, STAT: Signal Transducer and Activator of Transcription proteins, gp130: Glycoprotein 130, ARDS: Acute Respiratory Distress Syndrome.

A part of this figure is adapted and modified from the following commentary:

Addeo A, Obeid M, Friedlaender A. COVID-19 and lung cancer: risks, mechanisms and treatment interactions. J ImmunoTherapy Cancer, 2020; 8:e000892. 
Growing evidences suggest that there are many similarities between Macrophage Activation Syndrome (MAS) disease and COVID-19 pneumonia. Similarities include pathological findings and a "second wave" of cytokine secretion. The loss of "front line" anti-viral defence mechanism may be the causative agent for this "second wave" activation, and prolong IL-6 secretion ${ }^{32}$. Sustained IL-6 secretion has also been correlated to serum viral RNA load in critically ill patients ${ }^{33}$, and viral RNA load is in turn correlated to ARDS severity ${ }^{34}$. So, all these evidence indicating a possible detrimental role of IL-6 in SARS-CoV2 infection.

\section{IL-6 inhibitors and preliminary findings}

IL-6 inhibitors are categorized under immune-based therapies, separate from the antiviral therapies. Evidence from previous pandemics of SARS and MERS suggest no survival benefits with corticosteroids. Moreover, with use of corticosteroids, delayed viral clearance was observed from the respiratory tract and blood with associated complications including hyperglycemia, psychosis, and vascular necrosis ${ }^{35}$. Hence, corticosteroids are generally restrained in case of COVID-19 for specific situations like refractory septic shock ${ }^{35}$. However, selective immunosuppression is likely to be beneficial in the COVID19-associated states of pulmonary hyperinflammation. The targeted monoclonal antibodies against IL-6 can selectively dampen this process and improve clinical outcomes in patients with evident features of cytokine driven inflammation.

Tocilizumab (Actemra) and sarilumab (Kevzara) are antagonists of the IL- 6 receptors, with FDA approval to treat moderate-to-severe rheumatoid arthritis not responding to disease-modifying anti-rheumatic drugs (DMARDs) 36, 37. Another FDA-approved IL-6 receptor antagonist is siltuximab (Sylvant), which is used for the treatment of patients with multicentric Castleman's disease (MCD) who are HIV negative and human herpesvirus-8 (HHV-8) negative ${ }^{38}$. Preliminary evidence of efficacy in COVID-19 is available for tocilizumab through small studies.

One study was carried out in case of severe COVID-19 patients, which showed successful outcomes in 21 patients. Most of the patients were receiving only one dose of tocilizumab $400 \mathrm{mg}$ along with standard care, including lopinavir and methylprednisolone. It showed improved clinical outcomes in $91 \%$ of patients in terms of improvement in lung function and successful discharge with a mean of 15.5 days. But lack of a comparator group and blinding were important limitations ${ }^{39}$. Further, a retrospective observational study in 15 COVID-19 patients reported a good response in patients treated with tocilizumab and recommend repeated doses of tocilizumab in critically ill COVID-19 patients ${ }^{40}$. However, the number of cases reported was again small and the duration of treatment studied might not have been sufficient.

\section{Clinical Trials with IL-6 Inhibitors}

Several randomized controlled trials (RCT) (in excess of 50 in number) of tocilizumab, sarilumab and siltuximab, (IL-6 receptor antagonists) alone or in combination, are now proposed in patients with severe COVID-19, mainly in China, Western Europe, USA, Russia, Malaysia, and Australia ${ }^{41-43}$.

Some of the early initiated studies include a multicenter RCT of tocilizumab alone in patients with COVID-19 pneumoniaandelevated IL-6in China(ChiCTR2000029765) targeting 188 patients ${ }^{44}$. Another Chinese trial has initiated on 150 patients assessing tocilizumab in combination with favipiravir, a broad spectrum anti-viral agent (ChiCTR2000030894, NCT04310228) ${ }^{45}$.

Genentech, the innovator company of tocilizumab, has also initiated a randomized, double-blind, placebocontrolled Phase III clinical trial (COVACTA, NCT04320615) to evaluate the safety and efficacy of tocilizumab plus standard of care in hospitalized adult patients with severe COVID-19 pneumonia compared with placebo plus standard of care with an aim to recruit approximately 330 patients globally ${ }^{46}$.

In Denmark, there is an open-label, multicenter sequential and cluster randomized trial (TOCIVID, NCT04322773) to compare the effect of either one of three IL-6 inhibitor administrations (i.e. intravenous tocilizumab, subcutaneous tocilizumab, and subcutaneous sarilumab), relative to the standard of care, in patients with severe SARS-CoV2 pneumonia ${ }^{47}$.

For sarilumab, a Phase II/III trial of the intravenous formulation has been initiated in March 2020 by Sanofi and Regeneron, for hospitalized patients with severe COVID-19 (NCT04315298) in USA, Italy, Spain, Germany, France, Japan, Canada and Russia ${ }^{48}$. The double-blind trial has a flexible design with two parts and is anticipated to register up to 400 patients. The first part is recruiting patients across multiple sites in the USA and will evaluate the effect of sarilumab on fever and need for supplemental oxygen. The second part, which is the larger part of the trial, will evaluate improvement in longer-term outcomes, including prevention of mortality and reduction in need for mechanical ventilation, supplemental oxygen, and/or hospitalization. The early results from this study seem to show that its utility may be reserved for the 'critically' ill patients ${ }^{48}$.

Another open label randomized Phase II/III clinical trial (CORIMUNOSARI, NCT04324073) with sarilumab in COVID-19 patients with moderate, severe or critical pneumonia aims to compare the outcomes of sarilumab- 
treated patients with those receiving outcomes of standard of care as well as with patients being treated with other immunomodulators ${ }^{49}$.

A retrospective observational case-control study evaluating the use of siltuximab in patients diagnosed with COVID-19 infection who have developed serious respiratory complications is also registered in Italy (NCT04322188) ${ }^{43}$

\section{Role of other cytokines in COVID-19 cytokine storm}

Apart from IL-6, there are other cytokines which are responsible for cytokine storm in COVID 19 infection. Huang et al have reported that, apart from IL-6, increased circulating levels of other pro-inflammatory cytokines (e.g. Interferon $\gamma$, interleukin (IL-) $1 \beta$, IL-8, TNF- $\alpha$ ) are associated with pulmonary inflammation and extensive lung involvement in SARS-CoV2 patients ${ }^{23}$. Active IL-1 $\beta$ and IL-18 originate from their inactive precursors via a cleavage catalysed by caspase-1, an inflammatory cysteine protease which modulates inflammatory and host defense responses against pathogens by processing the precursor forms of the pro-inflammatory cytokines IL-1 $\beta$ and IL-18 into their biologically active forms ${ }^{50}$.

IL-1 $\beta$ and TNF- $\alpha$, mostly secreted by activated macrophages, and as a result, are present in high concentrations in broncho-alveolar lavage fluid (BALF) from patients with ARDS and stimulate neutrophil functions $s^{50-52}$.

Upon release from monocytes/macrophages and alveolar epithelial cells, IL-8 plays a key role in stimulating neutrophil survival and recruitment to the lungs ${ }^{52}$. IL-8 synthesis is effectively stimulated by IL-17A and IL-6dependent Th17 cells help in its secretion. All these are likely involved in triggering the cytokine storm associated with lung neutrophilic infiltration ${ }^{20}$. Indeed, high numbers of Th17 lymphocytes can be common phenomenon in peripheral blood of patients with severe SARS-CoV2 infection ${ }^{53}$.

In context to inflammatory cell influx into SARSCoV2-infected lungs, a key pathologic function is also exerted by GM-CSF, which mediates relevant intercellular communications between pathogenic Th1 cells and $\mathrm{CD}_{14}{ }^{+} \mathrm{CD} 16^{+}$monocytes ${ }^{18}$. High numbers of CD $14^{+} \mathrm{CD} 16^{+}$ monocytes are detectable in COVID-19 patients with severe involvement of lungs, where these cells actively participate in induction and amplification of tissue infiltration by macrophages ${ }^{18}$.

Another potentially involved proinflammatory mediator in the cytokine/chemokine storm in severe SARS-CoV2 infection is the chemokine IP-10. In fact, it has been previously shown that IP-10 is up-regulated in bronchiolar and alveolar epithelial cells, as well as in $\mathrm{T}$ cells and monocytes/macrophages infiltrating the lungs in case of SARS ${ }^{54}$. IP-10 exerts a strong chemotactic action on $\mathrm{T}$ lymphocytes, monocytes and natural killer cells ${ }^{54}$. It is thus very likely that IP-10 significantly contributes to the recruitment of monocytes/ macrophages into the lungs of SARS patients. Virus-induced production of IP-10 could also be responsible for a fast mobilisation, followed by a subsequent apoptosis of $\mathrm{T}$ cells ${ }^{54}$. This mechanism might be implicated in the impairment of T lymphocyte response against SARS-CoV2. Role of this proinflammatory cytokine IP-10 in disease progression has been described in Figure 2.

Role of $\mathrm{P} 2 \mathrm{X} 7$ receptor in caspase 1 activation and IL-1 $\beta$ release

Interleukin-1 $\beta$ (IL-1 $\beta$ ) plays a central role in the activation of innate immune system and inflammation and in several chronic inflammatory diseases. A better understanding of IL-1 $\beta$ synthesis and release is basically required and relevant for the design of novel antiinflammatory drugs. One of the molecules mainly involved in IL-1 $\beta$ maturation is the P2X7 receptor (P2X7R), an ATPgated ion channel that chiefly acts through the recruitment of the NLRP3 inflammasome-caspase-1 complex. Several reports underscore the pivotal role of ATP-mediated P2X7R activation in IL-1 $\beta$ release from activated immune cells like monocytes, macrophages, and microglia. Different reports have suggested that macrophages from genetically modified mice lacking the P2X7R, ASC (the adaptor molecule apoptosis-associated speck-like protein containing a CARD) or NLRP3, do not release IL-1 $\beta$ in response to ATP. Moreover, oxidized ATP, an irreversible blocker of the P2X7R has the ability to abrogate ATP-induced IL-1 $\beta$ release from immune cells. P2X7R stimulation also induces fast release into the cytosol of oxidized mitochondrial DNA (mitoDNA) that promotes NLRP3 inflammasome assembly by direct interaction. IL-1 $\beta$ maturation is catalyzed by ATP-mediated stimulation of the P2X7R that drives NLRP3 inflammasome assembly and caspase- 1 recruitment ${ }^{55}$.

Previous research have showed that pharmacological blockade of P2X7 receptors, or its genetic ablation, substantially reduced inflammatory cell infiltration, cytokine levels, and lung damage in acute inflammatory response. It is also reported that $\mathrm{P} 2 \mathrm{X} 7$ receptor deficiency also reduced alveolar macrophage death and pro-IL-1 $\beta$ release in the lungs of LPS-treated mice. On the basis of these convergent observations, it can be hypothesized that the P2X7 receptor could be an ideal candidate receptor for pharmacological targeting in Covid-19-associated ARDS. The P2X7 receptor has also been proposed as an inflammatory biomarker and its monitoring in Covid-19 has been recently suggested. But the therapeutic effect of P2X7 receptor blockade has never been tested in a disease condition characterized by uncontrolled hyperinflammation, as in Covid-19. So, in-depth research and controlled clinical trials are required before using 

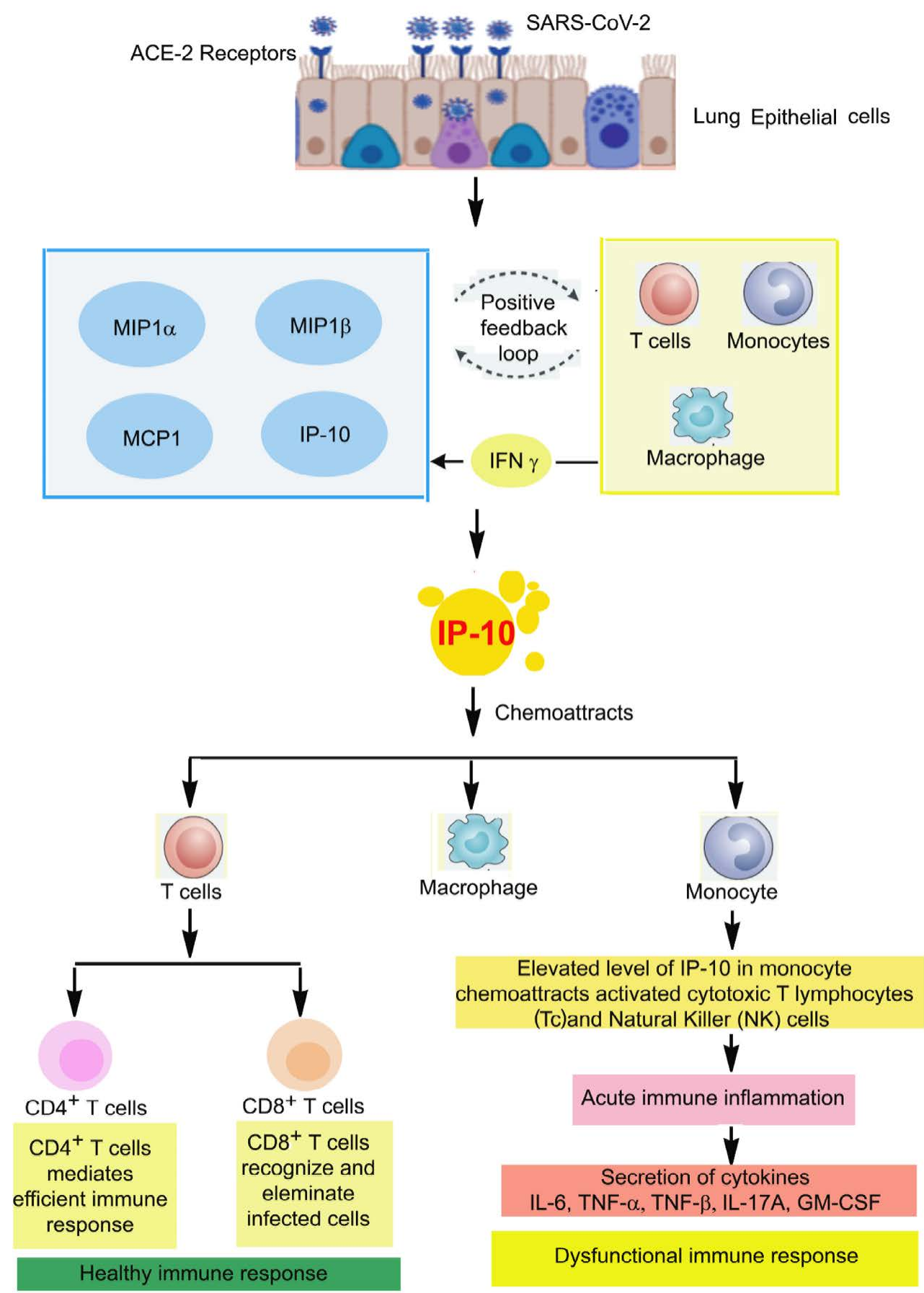

Figure 2: Mechanism of action of Chemokine IP-10 in immunomodulation during SARS-CoV2 infection

SARS-CoV2 infection is recognized by alveolar macrophages of human bronchial epithelial cells and triggers secretion of proinflammatory cytokines and chemokines. These proteins chemo-attracts monocytes, macrophages and T cells to the site of infection with the addition of IFN- $\gamma$ production by T cells and establishing a positive feedback loop.

IP-10 is highly induced in human bronchial epithelial cells especially by IFN- $\gamma$ induction. IP-10 is a potent chemoattractant for T cells, monocyets and macrophages. After SARS-CoV2 infection, elevated IP-10 in monocytes can chemoattracts activated cytotoxic $t$ cells (Tc) as well as natural killer (NK) cells leading to an acute inflammatory response and finally resulting secretion of different cytokines and thus cytokine storm.

On the other hand, initial inflammation attracts virus specific T cells to the site of infection where the infected cells can be eliminated before viral spread. So, these process lead to clearance of viruses and minimum lung damage.

ACE2: Angiotensin converting enzyme 2, NK: Natural killer Cells, MIP1- $\alpha$ : Macrophage inflammatory protein $1 \alpha$, MIP1- $\beta$ : Macrophage inflammatory protein $1 \beta$, MCP1: Monocyte chemoattractant protein 1 
P2X7 receptor as a potential therapeutic target for hyperinflammatory diseases like COVID-19 ${ }^{56}$.

\section{Therapeutic implications to control cytokine storm}

Several drugs, currently approved for treatment of various diseases and acting on different molecular targets, are potentially useful to lessen the strength of the cytokine storm triggered by SARS-CoV2. Such drugs include IL-6 receptor antagonists, IL-1 receptor antagonists, JAK/ STAT (Janus kinases/signal transducers and activators of transcription) inhibitors, corticosteroids, hydroxychloroquine and azithromycin. Now, in this part we are focusing our discussion about the drugs other than IL-6 inhibitors like IL-1 receptor antagonists, JAK/ STAT inhibitors, corticosteroids, hydroxychloroquine and azithromycin for the treatment of cytokine storm in COVID-19 infection.

\section{IL-1 receptor antagonist}

IL-1 is another proinflammatory cytokine playing a dominant role in a cytokine storm, and SARS-CoV2 may cause pyroptosis by IL-1 ${ }^{57}$. Anakinra is a recombinant IL-1R antagonist (rHIL-1Ra) and is the first IL-1 blocking biologic agent produced. Anakinra blocks the binding of both IL- $1 \alpha$ and IL- $1 \beta$ to IL-1R, thereby inhibits the proinflammatory effects of IL-1 ${ }^{58}$. Anakinra was found to be beneficial in patients with severe sepsis without significant adverse effects based upon the data of phase 3 randomized clinical trial ${ }^{59}$. The recommended subcutaneous (SC) adult dose of anakinra ranges from 100 to $200 \mathrm{mg}$ daily to $100 \mathrm{mg}$ three times weekly; the pediatric dose is $1 \mathrm{mg} / \mathrm{kg}$ daily. The bioavailability of SC injections is $95 \%$ with a half-life of 4-6 h. Hepatic disease does not require dose adjustment. The advantage of using Anakinra is unlike tocilizumab (TCZ), anakinra does not inhibit CRP synthesis directly; therefore, serum CRP levels can be used to follow up systemic acute phase response ${ }^{58}$. Anakinra is a recombinant antagonist of human IL-1 receptor that appears to be capable of improving the survival of septic patients with macrophage activation syndrome (MAS) ${ }^{60}$. In particular, in 43 septic patients with MAS and concomitant disseminated intravascular coagulation, hepatobiliary dysfunction, cytopenias and hyperferritinemia, when compared with placebo, anakinra treatment significantly improved the28-day survival rate (anakinra: 65.4\%; placebo:35.3\%) ${ }^{60}$.

Another molecule produced for IL-blockage is canakinumab, which is a high affinity, fully humanized, monoclonal anti-IL-1 $\beta$ antibody with $\operatorname{IgG1} / \kappa$ isotype. Following SC injection of $150 \mathrm{mg}$, peak serum concentration is achieved in 7 days. The recommended dose interval is every 2 months ${ }^{58}$. The third molecule developed for IL-1 blockade is Rilonacept, which is a recombinant soluble IL-1 receptor. The half-life of rilonacept is 6.3-8.6 days. The recommended loading dose is $2.2 \mathrm{mg} / \mathrm{kg}$, with the maximum dose of $160 \mathrm{mg}$; the maintenance dose is half of the loading dose weekly ${ }^{60}$. The use of canakinumab or rilonacept for severe COVID-19 infections has not been reported yet.

\section{Clinical Trial based on IL-1receptor antagonist therapy}

A phase 2/3, Randomized, open-label, parallel group, 3-arm, multicenter study is going on in Sweden (NCT04324021) to understand the efficacy and safety of emapalumab and anakinra in reducing hyperinflammation and respiratory distress in patients with COVID-19 infection ${ }^{61}$. Emapalumab IV infusion used every 3 rd day for a total 5 infusions. At day 1: $6 \mathrm{mg} / \mathrm{kg}$ dose was used and at days $4,7,10$, and $13: 3 \mathrm{mg} / \mathrm{kg}$ dose was optimised.

Anakinra IV infusion was administered four times daily for 15 days. The dose was $400 \mathrm{mg} /$ day in total, divided into 4 doses given every $6 \mathrm{~h}^{61}$.

From March 24 to April 6, 2020, 52 consecutive patients were included in the anakinra group and 44 historical patients were identified in the Saint-Joseph Groupe Hospitalier Paris for COVID cohort study ${ }^{62}$. Admission to the ICU for invasive mechanical ventilation or death occurred in 13 (25\%) patients in the anakinra group and $32(73 \%)$ patients in the historical group (hazard ratio [HR] $0 \cdot 22$ [95\% CI $0 \cdot 11-0 \cdot 41 ; \mathrm{p}<0 \cdot 0001]$. The treatment effect of anakinra group remained significant in the multivariate analysis (HR $0 \cdot 22$ [95\% CI $0 \cdot 10-0 \cdot 49]$; $p=0 \cdot 0002$ ). Moreover, an increase in liver aminotransferases level occurred in seven (13\%) patients in the anakinra group and four (9\%) patients in the historical group.

The above study indicates that, Anakinra reduced the need for invasive mechanical ventilation in the ICU as well as the mortality among patients with severe forms of COVID-19, without serious side-effects ${ }^{62}$. Although confirmation of efficacy will require further controlled trials.

Another retrospective cohort study was carried out by Martinenghi et al, in Italy, between March 17 and March 27, $2020^{63}$. In this study, 29 patients received highdose intravenous anakinra, non invasive ventilation, and standard treatment. Between March 10 and March 17, 2020, 16 patients received non-invasive ventilation and standard treatment only and comprised the comparison group for this study. A further seven patients received low-dose subcutaneous anakinra in addition to noninvasive ventilation and standard treatment; however, anakinra treatment was interrupted after 7 days because of a lack of effects on serum $\mathrm{C}$-reactive protein and clinical status. At 21 days, treatment with high-dose anakinra was associated with reductions in serum C-reactive protein and progressive improvements in respiratory function 
in $21(72 \%)$ of 29 patients; five (17\%) patients were on mechanical ventilation and three $(10 \%)$ died. In the standard treatment group, eight $(50 \%)$ of 16 patients showed respiratory improvement at 21 days; one $(6 \%)$ patient was on mechanical ventilation and seven (44\%) died. At 21 days, survival was $90 \%$ in the high-dose anakinra group and $56 \%$ in the standard treatment group $(\mathrm{p}=0.009)$. Mechanical ventilation-free survival was $72 \%$ in the anakinra group versus $50 \%$ in the standard treatment group $(\mathrm{p}=0 \cdot 15)$. Bacteraemia occurred in four (14\%) of 29 patients receiving high-dose anakinra and two $(13 \%)$ of 16 patients receiving standard treatment. Discontinuation of anakinra was not followed by inflammatory relapses.

So, this retrospective cohort study of patients with COVID-19 and ARDS managed with non-invasive ventilation outside of the ICU, treatment with high-dose anakinra was safe and associated with clinical improvement in $72 \%$ of patients. Further confirmation of efficacy will require controlled trials.

\section{Potential of JAK inhibitors in treatment of COVID-19 and some case reports}

Multiple small-molecule JAK inhibitors are used for the treatment of many inflammation driven pathologies such as inflammatory bowel disease, rheumatoid arthritis (RA), and psoriasis ${ }^{64}$. There are several JAK inhibitors currently approved by the US FDA and European Medicine Association like ruxolitinib ${ }^{65}$, baricitinib ${ }^{66}$, tofacitinib ${ }^{67}$, oclacitinib $^{68}$, and upadacitinib ${ }^{69}$ etc.

Studies have shown that SARS-CoV2 shares the same cell entry receptor, angiotensin converting enzyme II (ACE2), as SARS-CoV and it binds to the ACE2 receptors to infect host cells mainly through endocytic pathways ${ }^{14}$. With the help of artificial intelligence-derived knowledge graph, Richardson et al. initially reported that baricitinib (JAK1/2 inhibitor) may affect the cellular viral entry of SARS-CoV2 because of potential inhibitory effects on the known regulators of endocytosis, such as AP2-associated protein kinase 1 (AAK1) and cyclin G-associated kinase (GAK) ${ }^{70}$. Moreover, the therapeutic dose of baricitinib at either 2 or $4 \mathrm{mg}$ once daily is sufficient to effectively inhibit AAK1 and GAK ${ }^{71}$. Stebbing et al. later confirmed the anti-cytokine and antiviral activity of baricitinib by in-vitro experiments and reported that treatment with baricitinib improved the clinical condition in four patients with COVID-19 ${ }^{72}$. Moreover, baricitinib can serve as a good candidate for combination therapy (with remdesivir-an antiviral) as it has minimal interaction with CYP enzymes (involved in drug metabolism in the body) and low plasma protein binding ${ }^{72}$.

Recently Spinelli et al. highlighted the potential role of baricitinib in the management of COVID-19 patients ${ }^{73}$.
Tofacitinib is an effective oral pan-JAK inhibitor that is approved for use in RA, an autoimmune and inflammatory disease where cytokines play an important role in the disease pathogenesis ${ }^{74}$. It is a specifically potent JAK3 and TYK2 inhibitor (EC50 less than $5 \mathrm{nM}$ ) ${ }^{75}$ and thus can effectively block IL-2, IL-4, IL-6, and IL-7. Jacobs et al. recently reported a case of SARS-CoV2 infection in a woman with a 13-year history of ulcerative colitis, on tofacitinib. Despite testing positive for SARS-CoV2, the patient remained on the treatment of tofacitinib because of improved clinical symptoms without holding therapy. Two weeks later, all symptoms have been resolved without the necessity of hospitalization ${ }^{75}$. Although this does not prove that tofacitinib contributed to the recovery from COVID-19 in this case, it shows that the treatment of tofacitinib can potentially be continued in patients infected with SARS-CoV2. As studies that directly show benefits of use of tofacitinib in COVID-19 are not yet available, several clinical trials have been launched to investigate its potential benefits against the disease.

\section{Use of repurposing Drugs}

Drugs which have been tested as safe in human on early phases of clinical trials are always very tempting candidates for repurposing of drugs. In case of SARS-CoV2, conceptually, Broad spectrum antiviral agents (BSAA) are more advantageous as repurposing agents as they targets two or more viral families.

Umifenovir, a membrane fusion inhibitor which targets viral entry and Lopinavir/Ritonavir in combination target viral proteases are approved drugs for influenza and HIVs. These drugs are currently being used in various combinations in phase IV clinical trial for pneumonia associated with CoVID-19 (ID: NCT 04255017) ${ }^{76}$.

Remdesivir is a known viral RNA dependent RNA polymerase inhibitor and this is also under investigation for mild to moderate SARS-CoVID2 at the Phase III level (ID: NCT04252664). Moreover, viral polymerase inhibitor Favipiravir is under combination therapy in phase II clinical trial (Chinese Clinical Trial Registry Identifier ChiCTR 2000029544), and preclinical studies of Ribavirin (Ribonucleic analogue) has shown promising in-vitro activity against SARS-CoV2 ${ }^{76}$.

Chloroquine and Hydroxychloroquine - two antimalarial drugs affect endosomal function and blocks autopahgosome-lysosome fusion. Coronavirus use the endolysosomal pathway to enter the cell before uncoating. It is already proven that both drugs have been shown to inhibit SARS-CoVID2 replication in cellular models. A small randomized trial of HCQs in patients has reported a reduction in time in clinical resolution ${ }^{77}$.

Azythromycin (AZ) is a widely used broad spectrum antibiotic known to block autophagosome clearance 
in human cells and replication of influenza and zika virus in human cells in-vitro. A small open level trial has demonstrated that HCQs in combination with AZ showed better efficiency to decrease viral load compared to HCQs alone ${ }^{77}$.

Although in-vitro models suggest that hydroxychloroquine has anti-SARS-CoV2 activity, in case of either the randomized controlled trial (RCT) of patients with mild to moderate disease or in a large observational study of hospitalized patients hydroxychloroquine with or without azithromycin has not been shown to improve clinical outcomes ${ }^{78}$. In another widely publicized, singlearm study in France of 20 patients with mild to moderate disease who were treated with hydroxychloroquine showed reduced nasopharyngeal viral loads compared with the viral loads of patients from another center who were not treated with hydroxychloroquine. Clinical benefit was not reported. Another very recent RCT of 821 participants with high-risk exposure found no difference in symptomatic infection rates between those receiving hydroxychloroquine as post exposure prophylaxis (PEP) compared with those receiving placebo. So, it can be concluded that, after high-risk or moderaterisk exposure to Covid-19, hydroxychloroquine did not prevent illness when used as post exposure prophylaxis within 4 days after exposure. (Clinical Trials gov number, NCT04308668) ${ }^{79}$

However, both HCQs and AZ has detrimental side effects on eye and cardiac health. So, considering risk factors and benefits associated in each case of repurposing of drugs further guidelines should be made for further use of these drugs ${ }^{77}$.

Elmezayen et al, carried out a study to identify commercially available drugs in order to repurpose them against CoVID-19 by means of structure based virtual screening. This molecular docking study showed four potential inhibitors against *Mpro enzymes: two available drugs (Talampicllin and Lurasidone) and two novel drug like compounds (ZINC000000702323 and ZINC000012481889) ${ }^{80}$. [*Mpro is a key enzyme of coronaviruses and has a pivotal role in mediating viral replication and transcription. So, this could be a tempting drug target for SARS-CoV2 and different programmes are made to identify drug leads that can target main protease of SARS-CoV2 (Mpro)]

\section{Corticosteroids}

The use of systemic corticosteroids for treatment of COVID-19-associated cytokine storm could play a very important role. In fact, by modulating cytokine production, these drugs might repress hyperinflammation associated with COVID-19-related ARDS. The prospective metaanalysis from the WHO Rapid Evidence Appraisal for
COVID-19 Therapies (REACT) Working Group pooled data from 7 trials (RECOVERY, REMAP-CAP, CoDEX, CAPE COVID, and 3 additional trials) of total 1703 patients (678 had been randomized to corticosteroids and 1025 to usual care or placebo), of which $59 \%$ were from the RECOVERY trial. ${ }^{81}$ The 28-day mortality was lower in patients randomized to corticosteroids: 222 deaths among 678 patients randomized to corticosteroids compared with 425 deaths among 1025 patients randomized to usual care or placebo, with little heterogeneity across studies. ${ }^{81}$ The association between administration of corticosteroids and reduced mortality was similar for dexamethasone and hydrocortisone, suggesting the benefit is a general class effect of glucocorticoids and not specific to any particular corticosteroid.

On the basis of the preliminary report from the RECOVERY trial, the NIH COVID-19 Treatment Guidelines Panel has recommended using dexamethasone at a dose of $6 \mathrm{mg}$ per day for up to 10 days or until hospital discharge, whichever earlier, for both the treatment of hospitalized patients who are mechanically ventilated and for the patients who require supplemental oxygen but are not mechanically ventilated. In contrast, the Panel has given a negative recommendation of prescribing dexamethasone for the treatment of patients who do not require supplemental oxygen.

Based on the RECOVERY trial data, the panel has also suggested thatifdexamethasone is notavailable, alternative glucocorticoids such as prednisone, methylprednisolone, or hydrocortisone can be used in those cases.

\section{Targeting cytokine storm with Sirolimus to prevent severe progression of COVID 19}

mTOR is a central regulator of inflammation within the immune system as well as a sensor of oxidative stress. mTOR forms two complexes: mTORC1and mTORC2. mTORC1 mediates Th1 and Th17 differentiation at the time of viral antigenic presentation by dendritic cells (DC). mTORC2 mediates Th2 differentiation; while both complexes restrict regulatory T-cell (Treg) differentiation. In COVID-19, the serine/threonine kinase mTOR (mechanistic Target of Rapamycin) pathways may offer valuable targets to control cell injury, oxidative stress, and the onset of hyperinflammation ${ }^{82}$.

Rapamycin is the prototypic mTOR-inhibitor drug. Several analogs of Rapamycin have been synthetized for effective therapeutic use. In this context, Everolimus is a promising second-generation rapamycin derivative and is a specific inhibitor of mTORC1, which suppress mRNA translation, ribosome biogenesis, protein synthesis, mitochondrial metabolism, and adipogenesis ${ }^{83}$.

Classic mTOR inhibition by Rapamycin exerts opposite 
effects on conventional T lymphocytes and on $\mathrm{T}_{\text {regs }}$, and the differential impact is likely dependent on the intracellular state in the two cellular subpopulations ${ }^{84}$.

Briefly, cell growth of conventional $\mathrm{T}$ lymphocytes is inhibited by Rapamycin, but this drug promotes $\mathrm{T}_{\text {regs }}$ proliferation. Therefore, mTOR inhibition by drugs - and, specifically, the Everolimus-mediated mTORC1 inhibition may also assert this differential effect in COVID-19 cases. A reduction in proliferation of conventional Tymphocytes will help to diminish the cytokine storm, and on the other hand, $\mathrm{T}_{\text {reg }}$ growth and activity, could be helpful to reduce the hyper-reactivity in the critical phase of the disease ${ }^{82}$.

In addition, the mTOR pathway also plays a vital role in B cell development. mTORC1 controls BCL6 expression to control the fate of $\mathrm{B}$ cells in the germinal centre. Inhibition of mTORC1 reduces the populations of antigen specific memory B cells after B cell activation. Different reports have also suggested that mTOR inhibitors, rapamycin/ sirolimus, and ATP competitive inhibitors (INK128, PP242, $\mathrm{Ku}-0063794$, and AZD8055) have also been shown to suppress early B-cell production in germinal centers ${ }^{84}$.

It is well known that cross reactive antibody activates antibody dependent enhancement (ADE). If the activation of memory B cells can be selectively inhibited in these high-risk patients at an early stage to reduce the production of cross-reactive antibodies for SARS-CoV2, we can hypothesize that the ADE process can be avoided and severe symptoms can be reduced. Considering the role of mTOR inhibitors in limiting the proliferation of memory B cells, patients treated with mTOR inhibitors are expected to have reduced early cross-reactive antibody production and thus less ADE. In consideration of the pivotal role of mTOR in controlling cellular metabolism, pathogens have evolved elegant strategies to target this pathway within DCs and macrophage to promote immune escape. These studies elucidated new mechanistic characteristics of mTOR inhibitors and suggested immune applications beyond their role as immunosuppressants ${ }^{83}$.

Currently, two small-scale clinical trials using mTOR inhibitors or sirolimus in treating COVID-19 patients are ongoing (Clinicaltrials.gov Identifiers: NCT04371640 and NCT04341675) ${ }^{84}$. In case of second trial (NCT04341675), the investigators have employed a randomized, double blind, placebo-controlled study design. 30 subjects have randomized in a 2:1 fashion to receive sirolimus or placebo. Sirolimus has been given as a $6 \mathrm{mg}$ oral loading dose on day 1 followed by $2 \mathrm{mg}$ daily for maximum treatment duration of 14 days or until hospital discharge, whichever happens earlier. Chart reviews have been conducted daily to determine changes in clinical status, concomitant medications and laboratory parameters.
Study specific biomarkers have measured at baseline and then simultaneously at days 3, 7 and 14. The expected closure of this trial is in September 2020.

\section{Antiphospholipid antibody in the COVID-19 cases}

Thromboses are severe complications of the coronavirus disease 2019 (COVID-19). The mechanism of COVID19-associated thrombophilia is unknown; increasing global reports of antiphospholipid antibody (aPL)positivity in COVID-19 suggest that the virus may induce antiphospholipid syndrome (APS), a separate autoimmune thrombotic illness.

Gkrouzman et al have reported that, as of June 1st, 2020, 250 COVID-19 patients tested for aPL; 145 patients (58\%) were "positive" for aPL and Lupus anticoagulant (LA) was positive in $64 \%$ of cases, anticardiolipin (aCL) in $9 \%$, and anti- $\beta 2$ glycoprotein I antibody (aß2GPI) in $13 \%$ COVID positive patients. Although relevant clinical information (whether patients were receiving anticoagulation at time of LA testing or had prior history of positive aPL/APS) was not properly provided ${ }^{85}$.

\section{TNF- $\alpha$ inhibitors}

TNF- $\alpha$ is a key proinflammatory cytokine responsible for various acute and chronic inflammatory pathologies, including some autoimmune diseases and septic shock. Anti-TNF agents are widely used for the treatment of some autoimmunity disorders including rheumatoid arthritis, ankylosing spondylitis, and psoriatic arthritis. In case of SARS, serum TNF- $\alpha$ level are generally moderately elevated in patients, but much higher serum levels are observed in patients with COVID-19 infection, indicating a positive correlation with disease severity ${ }^{86}$. It is postulated that, the viral spike protein of SARS-Cov2 appears to induce TNF- $\alpha$-converting enzyme (TACE)-dependent alteration of ACE-2, which allows the virus to penetrate into host cells. As a consequence, the more TNF- $\alpha$ levels are elevated, the more this pathway is facilitated ${ }^{87}$. TNF antagonism in high cytokine states is a relatively unexplored field, with only a case report suggesting a potential benefit in macrophage activation syndrome caused by herpes simplex virus infection ${ }^{87}$. A clinical trial evaluating the effects of the TNF- $\alpha$ blocker adalimumab in COVID-19 infection is currently ongoing (ChiCTR2000030089).

\section{Intravenous Immunoglobulin (IVIG)}

Intravenous Immunoglobulin or IVIG can induce passive immunity, anti-inflammatory, and immunomodulatory effects that can improve therapeutic effects and increase survival in severe infection. Intravenous immunoglobulin (IVIg) is a pooled preparation of polyspecific, polyreactive immunoglobulin (Ig)G molecules from several thousand healthy donors. The immunoglobulin (Ig) molecule has Fab region, which is involved in antigen-binding and the 
Fc portion, which is involved in effector function. As IVIg is prepared from multiple donors, it contains numerous antibodies directed against a wide range of antigens; consequently, the variable regions on the Ig Fab fragments in IVIg preparations are diverse. The variable region can bind to non-self-antigens (foreign antigens), self-antigens and anti-idiotypic antibodies. IVIg contains a broad spectrum of antibody specificities against bacterial, viral, parasitic and mycoplasma antigens, that are capable of both opsonization and neutralization of microbes and toxins ${ }^{88}$. IVIg has also been shown to alter the cytokine network by mediating balance between different T helper (Th) types. Th cells can be classified into several subsets, such as Th1, Th2, Th17 and regulatory T cells, which produce distinct cytokines. Th1 cells produce cytokines such as interferon (IFN)- $\gamma$ and tumour necrosis factor (TNF)- $\alpha$, Th2 cells produce IL-4, IL-5, IL-13 and IL-10, Th17 cells produce IL-17, IL-21 and IL-22, and regulatory T cells which are immunosuppressor cells produce TGF- $\beta$ and IL-10 ${ }^{88}$.

Ma et al has described in detail a severe case of glandular fever treated with IVIG ${ }^{89}$. Levels of Th1 cytokines (IFN- $\gamma$, IL-12, soluble tumor necrosis factor receptor 1 (sTNFR1), CXCL10, CXCL9, CCL3), and viral loads eventually recovered after the combination of prednisolone with IVIG.

Cao et al, has reported high dose of immunoglobulin for treatment of COVID-19. In this case, patients received IVIG at the start of respiratory distress ${ }^{90}$. Results showed that, all 3 patients had clinical improvement; no fever within 1-2 days, alleviation of breathing difficulties in 3-5 days. But at the same time, limitation of this kind of study is that- it is small case series, with 2 patients also received antivirals, and 1 patient received steroids.

Xie et al carried out a retrospective review of 58 cases to study the effect of regular intravenous immunoglobulin therapy on prognosis of severe pneumonia in patients with COVID-19. In this study, the target population was ICU patients with severe or critical illness in Wuhan, China $(n=58){ }^{91}$. Results showed that administration of IVIG within 48 hrs of hospital admission was associated with reduced 28-day mortality, shorter hospital stay, and reduced ventilator use compared to administration after 48 hours. Similar to the previous report, the main limitation of this study is that it was a small retrospective study.

Apart from administration of IVIG, clinical administration of the blood component convalescent plasma from recovered SARS-CoV2 patients to those severely affected by the disease could be a safe option without adverse side effects. Moreover, a group of Chinese Scientists have reported that, they have isolated two monoclonal antibodies (mAb) from the memory B cell repertoire of recently recovered COVID-19 patients to prevent the entry of COVID-19 virus to the host cells and these mAbs have the potential to treat and or prevent SARS-CoV2 infection. These antibodies held best promise for treatment as they can prevent the viral spreading from cell to cell.

\section{Cytokine-Adsorption Device}

Cytokine adsorption is a process which involves extracorporeal membrane oxygenation (ECMO), to filter out harmful substances directly. An extracorporeal cytokine hemoadsorption device named Cytosorb (Cytosorbents, Monmouth, NJ, USA) has been reported to capture and reduce inflammatory mediators. Although this kind of devices are not made to kill or remove the viruses, these are generally used to absorb the cytokines and are promising tools to remove patients from ICU more faster and reliving the bottleneck.

Bruenger and his coworkers have observed that the plasma level of IL- 6 and procalcitonin were decreased in one patient with severe ARDS after treatment with ECMO support using a hemoadsorption device ${ }^{92}$. Moreover, a 45-year-old patient with severe ARDS showed that venous arterial-ECMO combined with hemoadsorption therapy helped to decrease plasma concentrations of IL-6 and IL-8. In addition to these, it was also reported that respiratory improvement, hemodynamic stabilization, and a decrease in capillary leakage can be reached by using combination therapy ${ }^{92}$. Two trials employing hemoadsorption therapy for infection-related cytokine storm are ongoing (NCT04195126, NCT03685383).

\section{Cytokine storm can be prevented by targeting the catecholamine cytokine axis}

Different research reports have shown that cytokine storm syndrome (CSS), known to be associated with bacterial infections, CAR-T cells, and other T cell-activating therapies, is also accompanied by a surge in catecholamines 93. Catecholamines contribute in inflammatory injury by enhancing the production of IL-6 and other cytokines through a self-amplifying feed-forward loop in immune cells that requires $\alpha-1$ adrenergic receptor ( $\alpha 1-\mathrm{AR})$ signalling ${ }^{93}$. In-vivo study suggested that, prophylactic inhibition of catecholamine synthesis by a tyrosine hydroxylase antagonist- metyrosine, reduced levels of catecholamines and cytokine responses and resulted in markedly increased various inflammatory stimuli in mice. Similar protection against a hyperinflammatory stimulus was observed with the well-tolerated $\alpha 1-A R$ antagonist, prazosin, demonstrating that this class of drugs can also prevent cytokine storm ${ }^{93}$.

Preliminary results from a recent retrospective clinical study revealed that, for hospitalized patients diagnosed with pneumonia or acute respiratory distress, the requirement of mechanical ventilation and mortality rate 
was significantly lower in case of patients treated with $\alpha 1$ AR antagonists during the year preceding hospitalization 93 .

These observations offer a rationale for studying $\alpha 1-\mathrm{AR}$ antagonists to prevent CSS and its appalling consequences in people who are at risk for developing severe COVID-19. This population includes people who are recently infected with SARS-CoV2 and people who are not yet infected but are at high risk zone of exposure. In this context, Prazosin is inexpensive and safe, as documented by long-term treatment of millions of patients with benign prostatic hyperplasia, hypertension, and other conditions. Although, all drugs can have unanticipated side effects in different clinical contexts, partially understood relationship between hypertension and COVID-19 suggests caution in using any agent that affects blood pressure ${ }^{92}$. Prospective clinical trials in high-risk patients are needed to assess $\alpha 1-\mathrm{AR}$ antagonist utility in preventing CSS in COVID-19 cases.

\section{Potential side effects of anti inflammatory treatments}

As cytokine storm is relatively common in severe case of COVID-19 infection and often leads to the exacerbation, anti-inflammation therapy may help in preventing further injury. Different research reports have suggested that, there are a variety of anti-inflammatory medications, including non steroidal anti-inflammatory drugs (NSAIDs), glucocorticoids, chloroquine/hydroxychloroquine, immunosuppressants, inflammatory cytokines antagonists (such as IL-6R monoclonal antibodies, TNF inhibitors, IL-1 antagonists, janus kinase (JAK) inhibitors etc.

Non-steroidal anti-inflammatory drugs (NSAIDs) have an optional prescription status that has resulted in frequent use, in particular for the symptomatic treatment of fever and non-rheumatic pain. In 2019, the multi-source analysis conducted by the CRPV [Centre Regional de Pharmacovigilance (French Regional Pharmacovigilence Centre)], which integrated complementary pharmacological data (clinical, pharmacoepidemiological, and experimental), confirmed and amplified the conclusions of the previous reports on the role of NSAIDs (in case of particularly ibuprofen, ketoprofen) in the aggravation of bacterial infections particularly in pulmonary infections ${ }^{94}$. First, the clinical observations of the French Pharmacovigilance Network showed that severe bacterial infections can occur even after a short NSAID treatment, and even if the NSAID is associated with an antibiotic. Second, pharmacoepidemiological studies, some of which minimized the protopathic bias, all converged and confirmed the risk. Moreover, the existence of a safer alternative option- paracetamol at recommended doses makes this recommendation of precaution and common sense even more legitimate ${ }^{95}$.
However, there is dilemma of anti-inflammatory therapy, balancing the risk and benefit ratio is a critical issue. There are certain questions regarding the exact dose, duration, regimen of the anti-inflammatory treatment which are still under intense debate and do not reach a consensus. The main concern is that anti-inflammatory medications, like corticosteroid, may delay the elimination of virus and increase the risk of secondary infection, especially in those with impaired immune system ${ }^{96}$. Secondly, biological agents targeting pro-inflammatory cytokines can only inhibit specific inflammatory factor, and thus may not be very effective in curbing the CS in COVID-19 in which other cytokines maybe of significant importance. Thirdly, some anti-inflammatory drug such as some JAK inhibitors has the ability to block interferon alpha production, which is important in fighting virus, and theoretically may not be suitable for the treatment of inflammatory CS caused by virus like COVID-19 ${ }^{97}$. Finally, it is very important to determine the time window of anti-inflammatory treatment. According to various reports till date, severe patients usually underwent abrupt deterioration in 1-2 weeks after onset, and prompt initiation of the anti-inflammatory therapy at this extremely short time period is likely to achieve a favourable treatment response. So, initiation of anti-inflammation treatment at the right window of time is of pivotal importance and should be tailored in individual patient to achieve the most favourable effects.

\section{Discussion}

In this review, the relation between pandemic COVID-19 infection, its immunologic complications, the mechanisms involved in cytokine storm development and why this complication occurs in some patients during COVID-19 infection were discussed and possible therapies reviewed.

Considering cytokine storm in COVID-19 cases, the elevated levels of IL- 6 and IL-10 are highly consistent in COVID-19. IL-6 targets the IL-6 receptor, and the later recruit JAK, which transit cascade signal to activate signal transducer and activator of transcription 3 (STAT3) ${ }^{98}$. Some physicians suggest that tofacitinib, a small molecule compound which targets JAK1 and JAK3, could be applied in the treatment of COVID-19, and tofacitinib also has succeeded in treating a COVID-19 patient complicated with ulcerative colitis ${ }^{75}$.

IL-10, an anti-inflammatory cytokine, could be secreted by virtually all immune cells, including macrophages, DCs, NK cells, T cells, and B cells ${ }^{99}$. As it is already reported that IL-10 can block the activity of NF-kB to downregulate the production of IL-6, we might tend to regard the high levels of IL-10 as negative feedback of counteracting the increase of IL- 6 . However, an abundance of IL-10 also inhibits the function and proliferation of immune cells (e.g., Th1, NK cells, and CD8 T cells), which delays the clearance of 
viruses ${ }^{99}$. Therefore, a mass of IL-10 might be responsible for the normal levels (one study report low level) of IFN- $\gamma$ (a cytokine for the clearance of viruses) and the exhaustion of lymphocytes. So, the IL-10 inhibitor in the treatment of COVID-19 also needs to be considered. Even the combination of IL-10 and IL- 6 inhibitor could be designed in future prospective studies. When using any method to regulate the dysregulation of cytokines, the laboratory index might be carefully maintained for preventing over treatment. Based on the therapeutic mechanisms, the remaining therapies can be classified as, corticosteroids, cytokine-adsorption devices, intravenous immunoglobulin, and antimalarial agents, as "less potential treatments." The benefits, dose, duration, and timing of corticosteroids are still in debate, and the other less potential treatments need clinical evidence to validate.

Although the experimental model of different infectious disease (e.g., malaria and sepsis) and autoimmune disease (e.g., Rheumatoid arthritis (RA) and Systemic lupus erythematosus (SLE)) indicates that artemisininfamily drugs could target the inflammatory networks to decrease the levels of cytokines (e.g., IL- 6 and TNF- $\alpha$ ) and chemokines (e.g., IL-8, CXCL10), the effect and safety of antimalarial agents still need to be validated in the highquality clinical studies and the SARS CoV2 infection disease model.

These kind of study although have some limitations. Firstly, the literature about COVID-19 is changing at great speed. The lack of standard published studies and the differences in the treatment approaches between different countries specially Chinese and Western sources remained an obstacle for making correct recommendations.

Moreover, there is increasing evidence that many patients with COVID-19 are asymptomatic or have only mild symptoms, but they are able to transmit the virus to others. There are difficulties in screening for asymptomatic infections, which makes it more difficult for national prevention and control of this epidemic. Early recognition of an infected person and cutting off the route of transmission are key points to control COVID-19. However, most asymptomatic infections do not seek medical assistance due to no obvious clinical signs and poor prevention awareness, and as a result, this contribute to the rapid spread of COVID-19. Therefore, it is a great challenge to prevent and control this specific type of patient globally. The most likely source of asymptomatic infections is close contacts of patients who have been diagnosed or suspected, and family members of those patients. Also, colleagues, friends, and people who coincide with the orbits of diagnosed or suspected patients are all regarded as high-risk populations. So these people, even without any symptoms, should be closely monitored and examined to rule out infection. These cases also highlight the need for a close epidemiological investigation for exclusion of possible sources of contamination.

Although SARS-CoV2 infections may be asymptomatic or cause only mild symptoms in most of the cases, immunologic complications such as MAS and cytokine storm may occur in some cases. Impairment of SARS-CoV2 clearance due to genetic and viral features, lower levels of interferons, increased neutrophil extracellular traps and increased pyroptosis are generally responsible for such complications. Early recognition and appropriate treatment of MAS and cytokine storm will decrease the morbidity and mortality in COVID-19 infection, which requires the collaboration of infectious disease, lung, and intensive care unit specialists with other experts such as immunologists, rheumatologists and, hematologists.

\section{Conclusion}

The sudden outbreak of SARS-CoV2 infection is currently associated with an ongoing progress in the knowledge of underlying pathogenic mechanisms, which is highlighting the immunophenotypic traits which characterize the infected patients more susceptible to the development of heavy lung damage caused by cytokine storm. Indeed, impairment in anti-viral immune response and the subsequent aberrant hyperinflammatory reaction can facilitate the occurrence of the most severe forms of COVID-19-related illness especially in elderly people with co-morbidity. Different case reports have stated that individuals with cardiac diseases, hypertension, and diabetes are more prone to SARS-CoV2 infection due to immune response dysregulation. The role of few medicines, especially ACE inhibitors is controversial in case of those individuals, suffering from diabetes, hypertension or other cardiovascular diseases since those drugs lead to ACE2 receptor overexpression, associated to SARS-CoV2 cell's entry. After virus entry into the cell, it multiplies until attain many copies, generating a more acute and late inflammatory response. As a consequence, cytokine storm occurs and it end up harming healthy cells. In order to regulate inflammation and reduce damage to healthy cells, Vitamin D can be a good choice, as it can modulate a favourable immune response and could hypothetically reduce levels of associated complications. A better understanding of cytokine storm pathobiology can also make it possible to explore the therapeutic efficacy of IL-6 receptor antagonists and JAK/STAT inhibitors, which, however, require to be further carefully evaluated by randomised controlled trials.

After outbreak of SARS-CoV2, researchers across the world are engaged to develop vaccines in more than 165 cases. Among them, 31 vaccines are in human trials and are showing promising results. Recently, on $11^{\text {th }}$ August, 2020, Russia approves first Corona vaccine, developed 
by the scientists of Gamaleya National Research Centre for Epidemiology and Microbiology (Sputnik V vaccine). Furthermore, Prof Sara Gilbert and her team in Oxford, UK, and another seven groups worldwide are carrying out phase 3 clinical trial and showing promising results. Vaccines typically requires years of research and testing before reaching the clinic but scientists are giving extra effort for quick generation of safe and effective vaccines in this pandemic situation. So, while we are waiting for a SARS-CoV2 vaccine, it can also be concluded that physical distancing and a better and controlled lifestyle which boost up our acquired immune responses can only help us to decrease the mortality rate associated with SARS-CoV2 related disease.

\section{Acknowledgement}

The authors would like to acknowledge all the lab members for their support during the preparation of this review article and finally acknowledge the Department of Biotechnology, NIT Durgapur for extending facilities for research work in the related field. CD was supported by DBT-RA fellowship.

\section{Conflict of Interest}

The authors declare that they have no conflict of interest with the contents of this article.

\section{References}

1. WHO. Novel Coronavirus (2019-nCoV) Situation Report 1. (2020). Available online at: https://www.who.int/docs/default-source/ coronaviruse/situationreports/ 20200121-sitrep-1 2019-ncov. pdf?sfvrsn=20a99c10_4.

2. World Health Organization. Director-General's remarks at the media briefing on 2019-nCoV on 11 February 2020. https://www.who.int/ $\mathrm{dg} /$ speeches/detail/who-director-general-s-remarks-at-the-mediabriefing-on-2019-ncov-on-11-february-2020.

3. Wit E, Doremalen NV, Falzarano D, Munster VJ. SARS and MERS: recent insights into emerging coronaviruses. Nat Reviews, 2016; 14: 524534 .

4. Gorbalenya AE, Baker SC, Baric RS, Groot RJD, Drosten C et al.The species Severe acute respiratory syndromerelated coronavirus: classifying 2019-nCoV and naming it SARS-CoV-2 Nat Microbiol, 2020; 5: 536-544

5. Y. Shi, Y. Wang, C. Shao, Huang J, Gan J et al. COVID-19 infection: the perspectives on immune responses, Cell Death Differ, 2020; 27 (5): 1451-1454.

6. Li H, Liu S.M, Yu X.H, Tang C.L, Tang C.K. Coronavirus disease 2019 (COVID-19): current status and future perspectives, Int. J. Antimicrob Agents, 2020; 55(5): 105951.

7. Chen Y, Liu Q Guo D. Emerging coronaviruses: genome structure, replication, and pathogenesis. J. Med. Virol, 2020; 92(4): 418-423.

8. Rossi PG, Broccoli S. Case fatality rate in patients with COVID-19 infection and its relationship with length of follow up. J Clin Virol, 2020; 128: 1044115.

9. Sun X, Wang T, Cai D, Hu Z, Chen J, et al. Cytokine storm intervention in the early stages of COVID 19 pneumonia. Cytokine Growth Factor Rev, (2020); 53: 38-42.
10. Mehta P, McAuley D.F, Brown M, Sanchez E, Tattersall R.S, Manson J.J. COVID-19: consider cytokine storm syndromes and immunosuppression, Lancet, 2020; 395(10229): 1033-1034.

11. Weiskopf D, Weinberger B and Grubeck- Loebenstein B. The aging of the immune system. Transpl Int, 2009; 22(11): 1041-1050.

12. Ahmadpoor P, Rostaing L. Why the immune system fails to mount an adaptive immune response to a Covid-19 infection. Transpl Int, 2020; 33(7): 824-825.

13. Zhou P, Yang XL, Wang XG ,Hu B, Zhang L, et al. A pneumonia outbreak associated with a new coronavirus of probable bat origin. Nature, 2020; 579 (7798): 270-273.

14. Hoffmann M, Kleine-Weber $\mathrm{H}$, Schroeder S, Kruger N, Herrler T et al. SARS-CoV-2 cell entry depends on ACE2 and TMPRSS2 and is blocked by a clinically-proven protease inhibitor. Cell, 2020; 181(2): 271-280.

15. Ceccarelli M, Berretta M, Rullo VE, Nunnari G, Ccopardo B. Differences and similarities between Severe Acute Respiratory Syndrome (SARS)CoronaVirus ( $\mathrm{CoV}$ ) and SARS-CoV-2. Would a rose by another name smell as sweet? Eur Rev Med Pharm Sci, 2020; 24: 2781-2783.

16. Sarzi-Puttini P, Giorgi V, Sirotti S, Marotto D, Ardizzone S, et al. COVID-19, cytokines and immunosuppression: what can we learn from severe acute respiratory syndrome? Clin Exp Rheumatol, 2020; 38(2): 337-342.

17. Chen J, Subbarao K. The immunobiology of SARS. Annu Rev Immunol, 2007; 25: 443-472.

18. Zhou Y, Fu B, Zheng X, wang D, Zhao C, et al. Pathogenic T cells and inflammatory monocytes incite inflammatory storm in severe COVID-19 patients. Natl Sci Rev, 2020; nwaa041.

19. Laderach D, Movassagh M, Johnson A, Mittler R. S, Galy A, et al. 4-1BB co-stimulation enhances human CD8+ $\mathrm{T}$ cell priming by augmenting the proliferation and survival of effector CD8+ T cells. Int Immunol, 2002; 14(10): 1155-1167.

20. Wu D, Yang X. O. TH17 responses in cytokine storm of COVID-19: an emerging target of JAK2 inhibitor fedratinib. J Microbiol Immunol Infect, 2020; pii: S1684-1182(20)30065-7.

21. Winiarska VO, Grywalska E, Roliński J. Could hemophagocytic lymphohistiocytosis be the core issue of severe COVID-19 cases? BMC Medicine, 2020; 18:214-226.

22. Fardet L, Galicier L, Lambotte O, Marzac C, Aumont C, et al. Development and validation of the HScore, a score for the diagnosis of reactive hemophagocytic syndrome. Arthritis Rheumatol, 2014; 66(9):2613-20.

23. Huang C, Wang Y, Li X, Ren L, Zhao J, et al. Clinical features of patients infected with 2019 novel corona virus in Wuhan, China. Lancet, 2020; 395(10223): 497-506.

24. Sarzi-Puttini P, Giorgi V, Sirotti S, Marotto D, Ardizzone S et al. COVID-19, cytokines and immunosuppression: what can we learn from severe acute respiratory syndrome? Clin Exp Rheumatol, 2020; 38: 337-342.

25. Velazquez-Salinas L, Verdugo-Rodriguez A, Rodriguez LL, Borca MV. The role of IL-6 during viral infections. Front Microbiol, 2019; 10: 1057.

26. Wang WK, Chen SY, Liu IJ, Kao CL, Chen HL et al. Temporal relationship of viral load, ribavirin, interleukin (IL)-6, IL-8, and clinical progression in patients with severe acute respiratory syndrome. Clin. Infect. Dis, 2004; 39(7):1071-1075.

27. Nagata N, Iwata N, Hasegawa H, Fukushi S, Harashima A et al. Mousepassaged severe acute respiratory syndrome-associated coronavirus leads to lethal pulmonary edema and diffuse alveolar damage in adult but not young mice. Am. J. Pathol, 2008; 172(6): 1625-1637. 
28. Day CW, Baric R, Cai SX, Frieman M, Kumaki Y et al. A new mouseadapted strain of SARS-CoV as a lethal model for evaluating antiviral agents in-vitro and in- vivo. Virology, 2009; 395(2):210-222.

29. Coomes EA, Haghbayan H. Interleukin-6 in COVID-19: A Systematic ReviewandMeta-Analysis.medRxiv 2020:2020.2003.2030.20048058.

30. Giamarellos-Bourboulis J, Netea MG, Rovina N, Akinosoglou K, Antoniadou A et al. Complex immune dysregulation in COVID-19 patients with severe respiratory failure. Cell Host Microbe, 2020; 27(6):992-1000.

31. Zhang X, Wu K, Wang D, Yue X, Song D et al. Nucleocapsid protein of SARS-CoV activates interleukin-6 expression through cellular transcription factor NF-kappaB. Virology, 2007; 365(2): 324-335.

32. McGonagle D, Sharif K, O'Regan A, Bridgewood C. The role of cytokines including interleukin-6 in COVID-19 induced pneumonia and macrophage activation syndrome-like disease, Autoimmun. Rev, 2020; 19(6):102537.

33. Chen X, Zhao B, Qu Y, Chen Y, Xiong J et al. Detectable serum SARSCoV-2 viral load (RNAaemia) is closely associated with drastically elevated interleukin 6 (IL-6) level in critically ill COVID-19 patients. Clin infect Dis 2020, ciaa449.

34. Chen W, Lan Y,Yuan X, Deng X, Li Y et al., Detectable 2019-nCoV viral RNA in blood is a strong indicator for the further clinical severity. Emerg. Microbes. Infect, 2020; 9(1):469-473.

35. Russell CD, Millar JE, Baillie JK. Clinical evidence does not support corticosteroid treatment for 2019-nCoV lung injury. Lancet, 2020; 395(10223):473-475

36. Tocilizumab: Drug information. [UpToDate website]. Available at: https ://www.uptod ate.com/conte nts/tocil izuma b-drug-informatio n\#F9773 765. Accessed 26 Apr 2020.

37. Sarilumab: Drug information. [UpToDate website]. Available at:https ://www.uptod ate.com/contents/saril umab-drug-information?sourc e=see_link\#F5013 3614. Accessed 29 Apr 2020.

38. Siltuximab: Drug information. [UpToDate website]. Available at:https ://www.uptod ate.com/conte nts/siltu ximab -drug-infor matio $\mathrm{n}$. Accessed 28 May 2020.

39. Cennimo DJ, Bergman SJ. Coronavirus Disease 2019 (COVID-19) Treatment \& Management. Updated. 2020. [Medscape] Available at: https ://emedi cine.medsc ape.com/artic le/25001 14-treatment\#d14. Accessed 6 May 2020.

40. Luo P, Liu Y, Qiu L, Liu X, Liu D, Li J. Tocilizumab treatment in COVID-19: a single centre experience. J Med Virol, 2020; 92(7): 814-818.

41. ClinicalTrials.gov [Internet]. Available at: https ://clini caltr ials. gov/ ct2/resul ts?cond=Covid $-19 \&$ term=tocil izuma b\&cntry =\&state $=\&$ city $=\&$ dist $=$. Accessed 28 May 2020 .

42. ClinicalTrials.gov [Internet]. Available at: https ://clini caltr ials.gov/ ct2/resul ts?cond=saril umab+COVID +19\&term=\&cntry=\&state $=\&$ city $=\&$ dist $=$. Accessed 28 May 2020 .

43. ClinicalTrials.gov [Internet]. Available at: https ://clini caltr ials.gov/ ct2/resul ts?cond=siltu ximab +covid +19\&term=\&cntry=\&state $=\&$ city $=\&$ dist $=$. Accessed 28 May 2020 .

44. Chinese Clinical Trial Registry. A multicenter, randomized controlled trial for the efficacy and safety of tocilizumab in the treatment of new coronavirus pneumonia (COVID-19). Available at:http://www.chictr org.cn/showprojen.aspx?proj=49409. Accessed 26 Apr 2020.

45. Favipiravir combined with tocilizumab in the treatment of corona virus disease 2019. Available at: https ://clini caltr ials.gov/ct2/ show/NCT04 31022 8. Accessed 8 May 2020.

46. A study to evaluate the safety and efficacy of tocilizumab in patients with severe COVID-19 pneumonia (COVACTA). Available at: https:// clini caltr ials.gov/ct2/show/NCT04 32061 5.Accessed 8 May 2020.
47. Anti-il6 treatment of serious COVID-19 disease with threatening respiratory failure (TOCIVID). Available at: https://clini caltr ials. gov/ct2/show/NCT04 32277 3. Accessed 8 May 2020.

48. Evaluation of the efficacy and safety of sarilumab in hospitalized patients with COVID-19. Available at: https://clini caltr ials.gov/ ct2/ show/NCT04 31529 8. Accessed 8 May 2020.

49. Cohort multiple randomized controlled trials open-label of immune modulatory drugs and other treatments in COVID-19 patientssarilumab trial-CORIMUNO-19-SARI (CORIMUNO-SARI). Available at: https://clini caltr ials.gov/ct2/show/ study /NCT04 324073. Accessed 8 May 2020.

50. Pinkerton JW, Kim RY, Robertson AAB, Hirota JA, Wood LG et al. Inflammasomes in the lung. Mol Immunol, 2017; 86: 44-55.

51. Jiang Y, Xu J, Zhou C,Zhengue W, Zhong S et al. Characterization of cytokine/chemokine profiles of severe acute respiratory syndrome. Am J Respir Crit Care Med, 2005; 171(8): 850-857.

52. Butt Y, Kurdowska A and Allen TC. Acute lung injury: a clinical and molecular review. Arch Pathol Lab Med, 2016; 140(4): 345-350.

53. Xu Z, Shi L, Wang Y, Zhang J, Huang L et al. Pathological findings of COVID-19 associated with acute respiratory distress syndrome. Lancet Respir Med, 2020; 8(4): 420-422.

54. Jiang Y, Xu J, Zhou C, Wu Z, Zhong S et al. Characterization of cytokine/ chemokine profiles of severe acute respiratory syndrome. Am J Respir Crit Care Med, 2005; 171(8): 850-857.

55. Giuliani AL, Sarti AC, Falzoni S, Virgilio FD. The P2X7 ReceptorInterleukin-1 Liaison. Front Pharmacol, 2017; 8: 123.

56. Virgilio FD, Tang Y, Sarti AC, Rossato M. A rationale for targeting the P2X7 receptor in Coronavirus disease 19. Br J Pharmacol, 2020; 1-5.

57. Yap JKY, Moriyama M, Iwasaki A. Inflamosomes and pyroptosis as therapeutic targets for COVID-19. J Immunol, 2020; 205:307-312.

58. Sahin A, Derin ME, Albayrak F, Karakaș B, Karagöz Y. Assessment of effectiveness of anakinra and canakinumab in patients with colchicine-resistant/unresponsive familial Mediterranean fever. Adv Rheumatol, 2020; 60(1):12.

59. Shakoory B, Carcillo JA, Chatham WW, Amdur RL, Zhao H, et al. Interleukin-1 receptor blockade is associated with reduced mortality in sepsis patients with features of the macrophage activation syndrome: re-analysis of a prior phase III trial. Crit Care Med, 2016; 44(2):275-281.

60. Varan Ö, Kucuk H, Babaoglu H, Guven SC, Ozturk MA, et al. Efficacy and safety of interleukin-1 inhibitors in familial Mediterranean fever patients complicated with amyloidosis. Mod Rheumatol, 2019, 29(2):363-366.

61. Coronavirus: Some Clinical Trial Data. Available from: https:// blogs.sciencemag.org coronavirus-some-clinical-trial-data.

62. Huet T, Beaussier H, Voisin O, Jouveshomme S, Dauriat G. Anakinra for severe forms of COVID-19: a cohort study. Lancet Rheumatol 2020; 2 e393-400.

63. Martinenghi S., Scotti R., Tresoldi M., Ciceri F., Landoni G., Zangrillo, A., et al. Interleukin-1 blockade with high-dose anakinra in patients with COVID-19, acute respiratory distress syndrome, and hyperinflammation: a retrospective cohort study. Lancet Rheumatol, 2020; 2: e325-331.

64. Schwartz DM, Bonelli M, Gadina M, O'shea JJ. Type I/II cytokines, JAKs, and new strategies for treating autoimmune diseases. Nat. Rev. Rheumatol, 2016; 12(1), 25-36.

65. Mascarenhas J. and Hoffman R. Ruxolitinib: the first FDA approved therapy for the treatment of myelofibrosis. Clin. Cancer Res, 2012 ; 18(11): 3008-3014. 
66. Mullard A. FDA approves Eli Lilly's baricitinib. Nat. Rev. Drug Discov, 2018; 17(7): 460.

67. Traynor K. FDA approves tofacitinib for rheumatoid arthritis. Am. J. Health Syst. Pharm, 2012; 69(24): 2120.

68. Damsky W, King BA. JAK inhibitors in dermatology: the promise of a new drug class. J. Am. Acad. Dermatol, 2017; 76(4), 736-744.

69. Duggan S, Keam S. Upadacitinib: first approval. Drugs, 2019; 79(16): 1819-1828.

70. Richardson P, Griffin I, Tucker C, Smith D, Oechsle 0 et al. Baricitinib as potential treatment for 2019-nCoV acute respiratory disease. Lancet, 2020; 395(10223), e30-e31.

71. Stebbing J, Krishnan V, de-Bono S, Ottaviani S, Casalini G et al. Mechanism of baricitinib supports artificial intelligence-predicted testing in COVID-19 patients. EMBO Mol. Med, 2020; e12697. http:// doi.org/ 10.15252/emmm.202012697

72. Stebbing J, Phelan A, Griffin I, Tucker C, Oechsle 0 et al. COVID-19: combining antiviral and anti-inflammatory treatments. Lancet Infect. Dis, 2020; 20(4): 400-402.

73. Spinelli FR, Conti F, Gadina M. HiJAKing SARS-CoV-2? The potential role of JAK inhibitors in the management of COVID-19. Sci. Immunol, 2020; 5(47):eabc5367.

74. Roskoski R. Jr. Janus kinase (JAK) inhibitors in the treatment of inflammatory and neoplastic diseases. Pharmacol. Res, 2016; 111: 784-803.

75. Jacobs J, Clark-Snustad K, Lee S. Case report of a SARS-CoV-2 infection in a patient with ulcerative colitis on tofacitinib. Inflamm Bowel Dis, 2020; 26(7):e64. doi: 10.1093/ibd/izaa093

76. Senanayake SL. Drug repurposing strategies for COVID-19. Future Drug Discov, 2020; eISSN 2631-3316.

77. Kiplin Guy R, DiPaola RS, Romanelli F, Dutch RE. Rapid repurposing of drugs for COVID-19: The emergence of a new coronaviral respiratory disease calls for repurposing existing drugs. Science, 2020; 368(6493): 829-831.

78. Gautret P, Lagier JC, Parola P, Hoang VT, Meddeb L et al. Hydroxychloroquine and azithromycin as a treatment of COVID-19: results of an open-label non-randomized clinical trial. Int J Antimicrob Agents, 2020; 56(1):105949.

79. Boulware DR, Pullen MF, Bangdiwala AS, Pastick KA, Lofgren SM et al. A randomized trial of hydroxychloroquine as postexposure prophylaxis for Covid-19. N Engl J Med. 2020;383(6):517- 525.

80. Elmezayen AD, Al-Obaidi A, S,ahin AT, Yelekc K. Drug repurposing for coronavirus (COVID-19): in silico screening of known drugs against coronavirus 3CL hydrolase and protease enzymes. J Biomol Struct Dynam, 2020;1-13. DOI: 10.1080/07391102.2020.1758791.

81. The WHO Rapid Evidence Appraisal for COVID-19 Therapies (REACT) Working Group. Association between administration of systemic corticosteroids and mortality among critically ill patients with COVID-19: a meta-analysis. JAMA. Published online September 2, 2020. doi:10.1001/ jama.2020.17023.

82. Terrazzano G, Rubino V, Palatucci AT, Giovazzino A, Carriero F et al. An open question: Is it rational to inhibit the mTor-dependent pathway as COVID-19 therapy? Front Pharmacol, 2020; 11:856.

83. Zheng Y, Li R, Liu S. Immunoregulation with mTOR inhibitors to prevent COVID-19 severity: A novel intervention strategy beyond vaccines and specific antiviral medicines. J Med Virol, 2020; 1-6.

84. Omarjeea L, Janinc A, Perrotd F, Laviollee B, Meilhacf O et al. Targeting T-cell senescence and cytokine storm with rapamycin to prevent severe progression in COVID-19. Clinical Immunology, 2020; 216 : 108464.

85. Gkrouzman E, Barbhaiya M, Erkan D, Lockshin MD. A reality check on antiphospholipid antibodies in COVID-19-associated coagulopathy. doi:10.1002/ART.41472.

86. Soy M, Keser G, Atagündüz P,Tabak F, Atagündüz I, Kayhan S. Cytokine storm in COVID-19: pathogenesis and overview of anti-inflammatory agents used in treatment. Clin Rheumatol, 2020; 39:2085-2094.

87. Iannaccone G, Scacciavillani R, Del Buono MG, Camilli M, Ronco C, et al .Weathering the Cytokine Storm in COVID-19: Therapeutic Implications. Cardiorenal Med, 2020; DOI: 10.1159/000509483.

88. Schwab I, Nimmerjahn F. Intravenous immunoglobulin therapy: how does IgG modulate the immune system? Nat Rev Immunol, 2013; 13(3): 176-89.

89. Ma C, Wong CK, Wong BC, Chan KC, Lun SW, et al. Cytokine responses in a severe case of glandular fever treated successfully with foscarnet combined with prednisolone and intravenous immunoglobulin. J Med Virol, 2009; 81(1):99-105.

90. Cao W, Liu X, Bai T, Fan H, Hong K et al. High-dose intravenous immunoglobulin as a therapeutic option for deteriorating patients with corona virus disease 2019. Open Forum Infect Dis, 2020; 7(3):ofaa102.

91. Xie $\mathrm{Y}, \mathrm{Cao} \mathrm{S}$, Dong $\mathrm{H}, \mathrm{Li} \mathrm{Q}$ Chen $\mathrm{E}$ et al. Effect of regular intravenous immunoglobulin therapy on prognosis of severe pneumonia in patients with COVID-19. J Infec, 2020; 81(2): 318-356.

92. Tang Y, Liu J, Zhang D, Xu Z, Ji J , Wen C. Cytokine Storm in COVID-19: The Current Evidence and Treatment Strategies. Front. Immunol, 2020; 11:1708. doi: 10.3389/fimmu.2020.01708.

93. Konig MF, Powell M, Staedtke V, Bai R-Y, Thomas DL et al. Preventing cytokine storm syndrome in COVID-19 using $\boldsymbol{\alpha}-1$ adrenergic receptor antagonists. J Clin Invest 2020; 130(7):3345-3347.

94. CRPV de Tours, CRPV de Marseille. Rapport d'expertise Infections bactériennes graves (de la peau et des tissus mous, pleuropulmonaires, neurologiques et ORL) rapportées avec l'ibuprofène ou le kétoprofène dans le traitement symptomatique de la fièvre ou de douleur non rhumatologique; 2019. https://www.ansm.sante.fr/ content/download/159487/ 2090277/version/1/file/Rapport+ PV AINS-Tours Marseille + 2019.pdf [Accessed May 4, 2020 (81 pp.)]

95. Micallef J, Soeiroa T, Jonville-Béra AP. Non-steroidal antiinflammatory drugs, pharmacology, and COVID-19 infection. Therapies, 2020; 75: 355-362.

96. Ni YN, Chen G, Sun J, Liang BM, Liang ZA. The effect of corticosteroids on mortality of patients with influenza pneumonia: a systematic review and meta-analysis. Critical Care, 2019; 23:99-108.

97. Boor PPC, de Ruiter PE, Asmawidjaja PS, Lubberts E, van der Laan LJW , Kwekkeboom J. JAK-inhibitor tofacitinib suppresses interferon alfa production by plasmacytoid dendritic cells and inhibits arthrogenic and antiviral effects of interferon alfa. Transl Res, 2017; 188:67-79.

98. Tanaka T, Narazaki M, Kishimoto T. IL-6 in inflammation, immunity, and disease. Cold Spring Harb Perspect Biol, 2014. 6:a016295. doi: 10.1101/cshperspect.a016295.

99. Rojas JM, Avia M, Martín V, Sevilla N. IL-10: a multifunctional cytokine in viral infections. J Immunol Res, 2017; 2017:6104054. doi: $10.1155 / 2017 / 6104054$.

100. Addeo A, Obeid M, Friedlaender A. COVID-19 and lung cancer: risks, mechanisms and treatment interactions. J ImmunoTherapy Cancer, 2020; 8:e000892. 